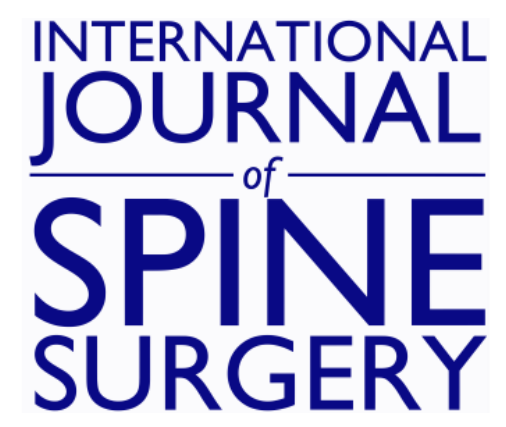

\title{
Revision of Minimally Invasive Sacroiliac Joint Fixation: Technical Considerations and Case Studies Using Decortication and Threaded Implant Fixation
}

Brett MenMuir and Louis C Fielding

Int J Spine Surg 2017, 11 (1)

doi: https://doi.org/10.14444/4008

http://ijssurgery.com/content/11/1/8

This information is current as of April 26, 2023.

Email Alerts Receive free email-alerts when new articles cite this article. Sign up at:

http://ijssurgery.com/alerts

The International Journal of Spind Surgerhi 2397 Waterbury Circle, Suite 1,

Aurora, IL 60504, Phone: +1-630-375-1432

(C) 2017 ISASS. All Rights Reserved. 


\section{Revision of Minimally Invasive Sacroiliac Joint Fixation: Technical Considerations and Case Studies Using Decortication and Threaded Implant Fixation}

Brett MenMuir, MD, 1 Louis C Fielding, $M S^{2}$

${ }^{1}$ Reno Orthopedic Clinic, Reno, NV ${ }^{2}$ Tahoe Labs, LLC, San Carlos, CA

\section{Abstract}

\section{Background}

Sacroiliac joint (SIJ) disease is increasingly recognized as a common source of low back pain. Arthrodesis of the SIJ has been shown to be clinically effective for this condition. In the last decade, minimally invasive (MI) SIJ fusion procedures have been developed to achieve the clinical effectiveness of open fusion procedures, with lower operative morbidity and faster recovery. However, SIJ fusion patients occasionally present with symptomatic nonunions necessitating revision.

\section{Methods}

Four patients who previously underwent MI SIJ arthrodesis returned with complaints of SIJ related pain confirmed by examination. Radiographic assessment showed lucency after fixation with triangular titanium interference implants. Loose implants were removed, and the patients were revised with a different MI SIJ fusion system that utilizes decortication, placement of autograft and graft extender, and fixation with cannulated threaded implants. The trajectory of the revision implants was in a more ventral-to-dorsal and caudal-to-cranial trajectory to place the implants perpendicularly through the articular portion of the SIJ.

\section{Results}

The triangular implants typically exhibited haloing lucency on radiographs and CT scans, and most were easily removed using the manufacturer's instrumentation; only one implant was left in place as it was well-fixed. The removed implants exhibited little or no bony ongrowth. Decortication of the SIJ was performed, followed by placement of local autograft and fixation with $12.5 \mathrm{~mm}$ or $14.5 \mathrm{~mm}$ diameter implants, as required. A more ventral-todorsal and caudal-to-cranial trajectory was established for the revision implants through the center of the articular region of the joint in order to maximize implant purchase in residual bone stock and achieve bony fusion through the articular portion of the SIJ. By six to twelve months post-revision, the presenting symptoms were successfully resolved in all patients.

\section{Conclusions}

Patients demonstrating symptomatic pseudoarthrosis after SIJ fixation surgery can be successfully revised with decortication, grafting and fixation with threaded implants utilizing MI surgical techniques. Implant trajectory is an important consideration for primary or revision MIS SIJ fusion. Studies with longer-term follow-up of both primary and revision procedures are needed to further understand fusion rates for both primary and revision procedures utilizing both triangular and threaded implant systems.

MINIMALLY INVASIVE SURGERY

KEYWORDS: SACROILIAC JOINT FUSION, REVISION, MINIMALLY INVASIVE, IMPLANT LOOSENING

VOLUME 11 ISSUE 1 DOI: $10.14444 / 4008$

PAGES 50 - 58

\section{Introduction}

Lower back pain (LBP) is a debilitating condition with significant cost to society. ${ }^{1}$ The sacroiliac joint
(SIJ) is increasingly recognized as a significant source of LBP, and accounts for as much as $30 \%$ of patients with axial LBP. ${ }^{2-5}$ When conservative care has failed, fusion of the SIJ is typically performed. In recent 
decades, minimally invasive surgery (MIS) procedures have become the dominant technique for SIJ arthrodesis. MIS procedures have been shown to have superior outcomes to both open SIJ fusion ${ }^{6}$ and nonoperative care. ${ }^{7,8}$

Despite the popularity and general success of MIS techniques for SIJ fixation or fusion, implant loosening and return to pain does occur and sometimes requires revision of the surgical construct. Miller et al. reported a $1.8 \%$ revision rate at a median of four months, and Cher et al. report a cumulative revision rate of $3.54 \%$ at four years for SIJ fixation with MIS procedures utilizing triangular titanium implants. ${ }^{9,10}$ Causes for revision in these studies included implant malpositioning and symptom recurrence. ${ }^{9,10}$ Both studies relied upon data voluntarily reported to the manufacturer; thus, the true revision rate is likely higher.

We report four cases of revision surgery after symptomatic nonunion with prior SIJ fixation. All patients presented with a return of SIJ pain, confirmed by provocative tests and/or injections. All were successfully revised with MI techniques that included decortication of the SIJ, placement of local autograft and cannulated, threaded implants. Specific findings, techniques and recommendations for SIJ fusion performed with MIS techniques are discussed.

\section{Revision Procedure: Technical}

\section{Considerations}

Preoperative Assessment of Recurrent SIJ Pain

As with a primary MI SIJ fusion procedure, accurate diagnosis of recurrent SIJ pain is critical, with the current gold standard including manual provocative tests and diagnostic injections. Manual provocative tests include the flexion-abduction-external rotation (FABER), Gaenslen, compression, thigh thrust and distraction tests, with three or more positive results indicating a reliable diagnosis of SIJ pain. ${ }^{11}$ Comparative, controlled anaesthetic blocks are useful to confirm the diagnosis. ${ }^{12,13}$ Conventional imaging studies (x-ray, MRI, CT) are typically not reliable for identifying pain-generating SIJ abnormalities ${ }^{12}$ however in the case of recurrent, postoperative SIJ pain, imaging studies are important to assess the condition of the implants. Lucency around the symptomatic implants is often visible on plain-film x-ray images.

\section{Surgical Technique}

Implant Removal

For cosmetic purposes, the revision procedure may be performed through an incision in the scar from the initial procedure. It is important to note, however, that remodeling during healing often causes the original scar to drift; intraoperative imaging is critical to correctly locate the implants to be removed. Biplanar C-arm fluoroscopy is sufficient to locate and orient the implants and anatomy. Alternatively, Oarm imaging would also be appropriate if available. A threaded extractor tool provided by the manufacturer is utilized to remove the triangular titanium SIJ implants. The extractor is used to locate the triangular implants and palpate the central threaded hole. Note that the ends of the implants and threaded holes are typically covered by fibrous tissue, which may require light tapping and pressure with the extractor to penetrate, taking care to not damage the internal threads of the implants.

With imaging, the extractor is aligned coaxially with the implants and carefully threaded in. To confirm that the implants are loose, the engaged extractor is lightly tapped such that motion of the implants will be readily apparent on imaging. Implants confirmed to be loose are typically easily removed by drawing the extractor out by repeated lateral (outward) impacts with a slap hammer. Implants that feel and appear tightly fixed may be left in place.

\section{Revision Implant Placement}

Our preferred revision implant system utilizes a decorticator and cannulated, threaded implants (SImmetry, Zyga Technology, Inc., Minnetonka, $\mathrm{MN}){ }^{14,15}$ The decortication and cannulated design of the implants promotes a larger fusion mass across the SIJ, while the threaded design of the implants provides superior mechanical fixation in the residual bone stock. The technique has been previously described, ${ }^{15}$ and briefly, involves drilling an osseous tunnel through the ileum into the sacrum, circumferential decortication of the SIJ around the tunnel, and placement of the threaded implants. 
Placement and trajectory of the revision implants are critical to ensure good purchase in the residual bone stock. The threaded implant system utilizes two implants (versus three triangular implants). In most cases, sufficient residual bone stock is available cranial or caudal to the original implants for placement of the revision implants. If residual bone stock is not sufficient or the placement is otherwise preferable, the largest $(14.5 \mathrm{~mm})$ threaded implants may be placed into the voids left by the triangular implants. While SIJ implants are commonly and intuitively placed in a direct lateral-to-medial trajectory, the preferred trajectory is angled both ventral-to-dorsal and caudal-to-cranial. The ventral-to-dorsal trajectory permits the implants to be placed through the articular portion of the SIJ, while the caudal-to-cranial approach is more perpendicular to the joint surface and allows use of longer implants.

\section{Case Reports}

Case 1

A 75-year-old female non-smoker presented with right buttock pain, which increased when changing positions, particularly between sitting and standing. The patient had a right SIJ fixation procedure approximately two years prior with three triangular titanium implants placed across the SIJ. The patient had also undergone an $\mathrm{L} 4 / 5$ pedicle screw fusion prior to the index SIJ fusion procedure. The patient reported a return to pain, which measured $6 / 10$ on the visual analog scale (VAS) with tenderness on the right SIJ sulcus and positive flexion-abduction/external rotation (FABER) and Gaenslens provocative tests. ${ }^{11} \mathrm{X}$ ray imaging revealed lucency around all three triangular implants. CT images also confirmed lucency around the implants and a lack of osseous bridging (Figure 1).

All triangular implants were removed. The cannulations of the triangular implants were quickly located using biplanar fluoroscopy with $\mathrm{C}$-arms positioned for simultaneous lateral and anteroposterior images. The superior implant was located first, and the manufacturer's removal instrument was tapped into its cannulation gently and with rotation - this was done carefully because the removal instrument can be difficult to seat through the fibrous layer that typically covers the head of the implant. Once seated, the removal instrument was tapped forward (medially) to confirm that the implant was loose as observed under fluoroscopy. At this point the implant was easily removed with repeated outward (lateral) impacting with a slap hammer. The inferior two implants were easily removed in the same fashion as the first. Bony ongrowth was not observed on any of the removed implants.

The revision procedure incision was placed caudal to the implant removal incision to achieve a more ventral start point targeting the articular portion of the joint. Decortication was performed using a purposespecific instrument (SImmetry, Zyga Technology, Inc., Minnetonka, MN), followed by placement of autograft mixed with demineralized bone matrix (DBX, Synthes, Inc., West Chester, PA). Finally, the joint was fixated with a $12.5 \mathrm{~mm}$ diameter $\mathrm{x} 60 \mathrm{~mm}$

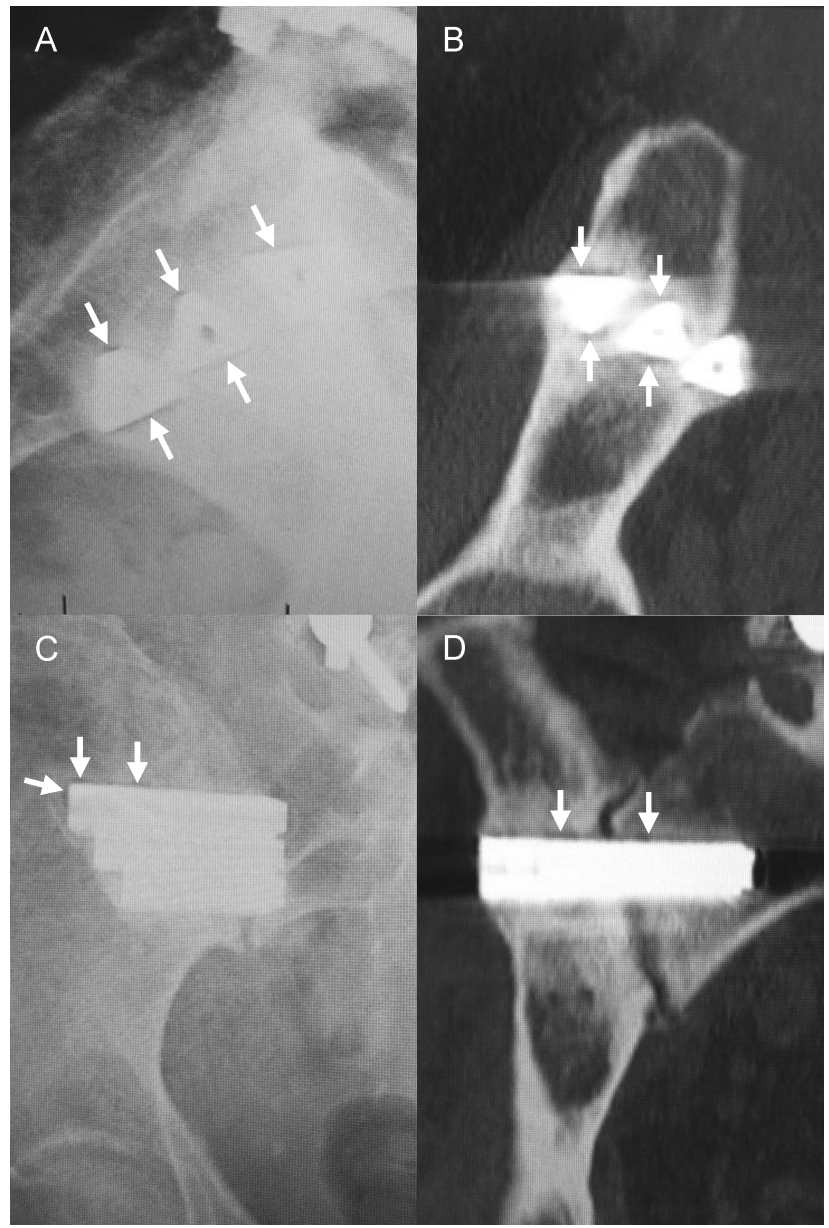

Fig. 1. Case 1 pre-revision $x$-ray $(A, C)$ and $C T(B, D)$ images, demonstrating halos around the triangular implants (arrows), and a lack of bridging bone across the SIJ (D). 
long threaded implant. ${ }^{15}$ Decortication, grafting and implant placement were repeated at the level of S2 using a similar trajectory (Figure 2).

The patient was discharged within 24 hours and allowed partial weight bearing of the right leg for three weeks. Two weeks following the revision procedure the patient reported a $30 \%$ decrease in pain to VAS 4/ 10. Radiographs obtained at the same visit found the implants in place with no loosening. At two months post-revision, the patient reported no pain over the right SIJ sulcus and $100 \%$ improvement with a VAS of $0 / 10$.

\section{Case 2}

Case 2 was similar to Case 1, but one triangular implant was left in place. The patient was a 78-year-old male non-smoker who had undergone right SIJ fixation with three triangular titanium implants approximately one year prior. Upon return to the clinic, the patient complained of pain in the right buttock and groin with a reported VAS of 10/10. The patient had tenderness to palpation of the right SIJ sulcus and positive FABER, Gaenslen and compression provocative tests. A diagnostic injection provided positive relief of the buttock and groin pain for less than one week. X-ray and CT imaging revealed possible halo lucencies around the triangular implants and no osseous bridging.

During revision the superior triangular implant was found to be stable and was left in place, but the two inferior implants were loose and easily removed.

There was no adherent bony ongrowth observed on the removed implants. Decortication was performed as described above, followed by placement of local al-

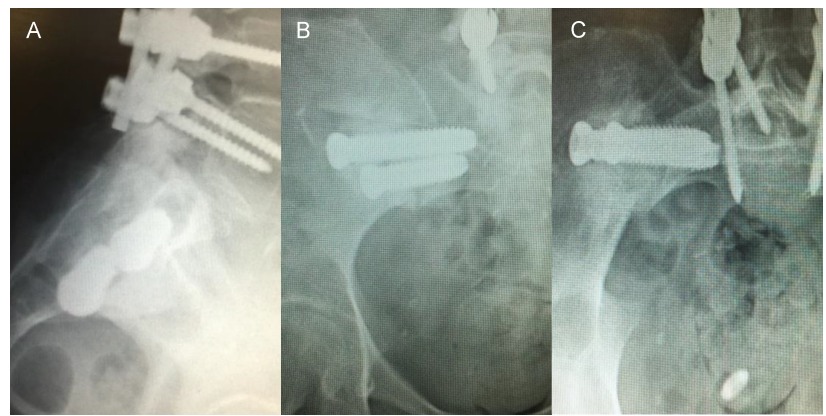

Fig. 2. Case 1 post-revision lateral (A), outlet (B) and inlet (C) x-ray images. The threaded implants are placed more ventrally through the articular region. lograft with Progenix (Biohorizons, Birmingham, $\mathrm{AL}$ ) and a $14.5 \mathrm{x} 40 \mathrm{~mm}$ threaded implant. The short implant length was chosen to avoid both the foramen as well as contact with the remaining triangular implant. Its larger diameter was selected to accommodate for the short length and proximity to the hole left by the removed implant. Decortication, grafting and placement of a $12.5 \times 40 \mathrm{~mm}$ threaded implant was performed inferiorly directed at the $\mathrm{S} 2$ foramen. Here the shorter length was chosen to stay short of the foramen. The start points of both implants were ventral to those of the triangular implants, and both had a ventral-to-dorsal trajectory, which kept the paths of the implants free from interaction with those of the previously-placed triangular implants.

The patient was discharged within 24 hours with partial weight bearing instructions. Two weeks postrevision the patient reported that the buttock pain had resolved, with a $70 \%$ improvement in pain $(3 / 10$ VAS), and the implants appeared well fixed in $\mathrm{x}$-ray images. Five months post-revision, the patient reported $80 \%$ improvement (VAS 2/10).

\section{Case 3}

Case 3 involved a 76-year-old woman who had undergone SIJ fixation with three triangular implants in her left SIJ more than two years previously. The patient reported VAS back pain of $7 / 10$, which increased when getting in and out of a chair. Provocative FABER and Gaenslens tests were both positive. Both $\mathrm{X}$-ray and CT imaging demonstrated lucencies around the triangular implants and no osseous bridging was observed across the SIJ.

All three triangular implants were easily removed with the manufacturer's extraction tool, and again there was no adherent bone observed on the implants. A $12.5 \times 55 \mathrm{~mm}$ threaded implant (superior) and $12.5 \times 40 \mathrm{~mm}$ threaded implant (inferior) were placed in the articular region of the joint following decortication and placement of autograft mixed with DBX. The patient was discharged within 24 hours and instructed to limit activity to partial weight bearing on the left leg for three weeks.

At two weeks post-revision, the patient reported no more buttock pain (VAS 3/10), and radiographic 
findings revealed no implant loosening. Two and six months post-revision, the patient reported complete recovery and resolution of pain (VAS 0/10). Twelve months post-revision, the patient continued to report significant improvement (VAS 3/10). No signs of implant loosening were found in radiographic imaging.

\section{Case 4}

Case \#4 involved a 78-year-old female (non-smoker) who had undergone bilateral SIJ fusion with triangular titanium implants, approximately 2 years prior. The patient reported right buttock pain had returned that increased when changing position and VAS back pain $7 / 10$. The patient had tenderness to palpation at the right SIJ sulcus and positive FABER test. Two injections were performed providing 1-2 weeks relief. $\mathrm{X}$-ray and CT imaging revealed halo lucency around all three right triangular implants. The right implants were notably placed in the dorsal portion of the SIJ (Figure 3).

Revision surgery was performed in August 2015. All three right triangular implants were extracted without difficulty, again with no adherent bone observed. The articular portion of the SIJ was decorticated and fixed with two implants as described in Case $1 .^{14,15}$ The more ventral placement, as well as the caudalto-cranial and ventral-to-dorsal trajectories of the revision implants compared to the more directly lateral-to-medial trajectories of the original implants can be clearly appreciated in the pre- and postrevision images (Figure 3, Figure 4). The patient was discharged within $24 \mathrm{hrs}$ with instructions for partial weight bearing for three weeks.

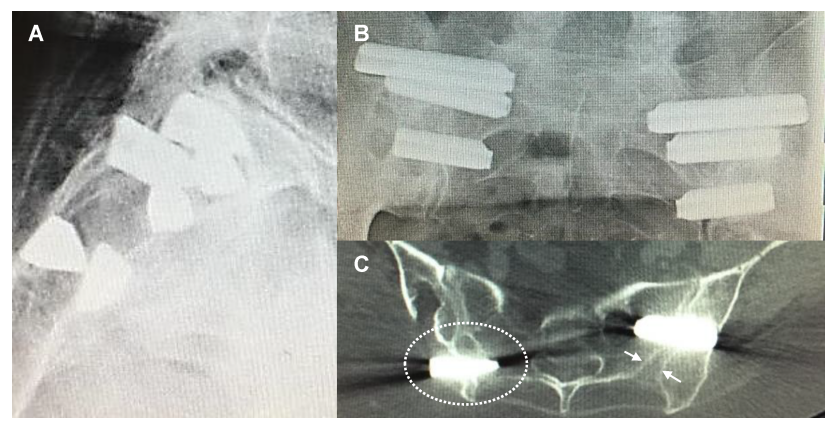

Fig. 3. Case 4 pre-revision images: lateral (A), A/P (B), and axial CT image (C), where it can be seen that the right implant (circled) is placed in the dorsal portion of the SIJ, through the interosseous gap (arrows indicate the interosseous gap on the contralateral side).
Two weeks postoperatively, the patient reported 50\% reduction in pain (VAS $3 / 10$ ), and imaging revealed no implant loosening. Two months postoperatively, the patient reported an $80 \%$ reduction in pain (VAS $1 / 10$ ) and no implant loosening was evident on radiographic imaging. Twelve months post-revision, the patient reported $80 \%$ improvement in her SIJ pain (VAS 1/10). Imaging findings were normal with the implants well-fixed and fusion apparent on CT.

\section{Discussion}

All four cases of revision SIJ fixation presented with similar characteristics. All had received previous SIJ fixation with triangular titanium implants 1-2 years prior and experienced a return of SIJ pain symptoms as observed using multiple diagnostic criteria including palpation, provocative tests and injections. Removal of all triangular implants on the symptomatic side was attempted in all patients, but implants that were found to be well-fixed upon attempted removal were left in place. A secondary SIJ fusion procedure was then conducted, which involved decortication, grafting and fixation with fully threaded implants.

Prior to revision, halo lucencies were observed around most implants, and there was no osseous bridging across the joint apparent on CT. These factors suggest that the pain was mechanicallymediated, that the initial fixation failed to sufficiently limit motion, and that the surgical construct required revision. Most implants were easily removed and exhibited no bony ongrowth. Although it has been speculated that such lucency on triangular implants represents artifact, ${ }^{16}$ these clinical and operative find-

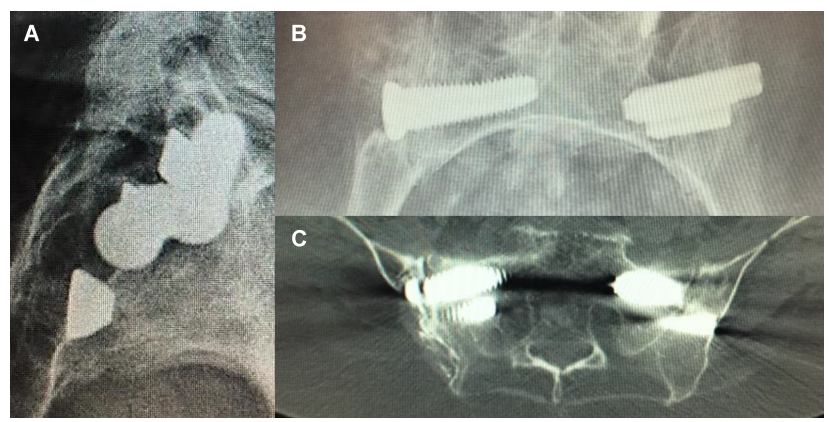

Fig. 4. Case 4 post-revision images showing the more ventral placement of the revised implants, as well as the more caudal-to-cranial and ventral-to-dorsal trajectories: lateral (A) and inlet view (B) X-rays; axial CT slice (C). 
ings confirm that the implants were indeed loose. This correlation is not surprising because it parallels that seen with porous coated ingrowth hip prostheses. ${ }^{17}$ In one patient, one implant could not be removed and was left in place. Radiographs did not illustrate lucency around this particular implant, and its location did not obstruct subsequent fixation. In general, removal of well-fixed implants is not considered necessary in our practice. However, the possibility that one or more implants are well-fixed in the ilium but loose in the sacrum should be considered; such a condition would interfere with decortication and fixation without contributing to construct rigidity. Alternate modes of decortication and fixation may be considered (e.g., open posterior access and decortication with pedicular fixation), however we prefer the MI approach to SIJ fixation when feasible.

The preferred trajectory for our revision implants follow a ventral-to-dorsal trajectory, which is in contrast to the lateral-to-medial trajectory of the revised triangular implants (Figure 5). The ventral-to-dorsal trajectory places decortication and fixation in the synovial articular region of the $\mathrm{SIJ}^{18}$ rather than the dorsal interosseous region, which has a much larger gap (see Figure 6). ${ }^{18,19}$ The smaller gap in the articular region provides a shorter distance for bony fusion to bridge across the joint, and allows for improved fixation compared to more dorsal placement across the larger gap. The lateral-to-medial trajectory may seem more intuitive; the initial teaching according to the triangular implant manufacturer was even to place the implants dorsally, with a ventral trajectory. However, these trajectories can result in one or more implants placed in the dorsal interosseous gap of the joint. Such dorsal placement is likely biomechanically inferior vs. placement in the articular region. This point is especially important with shorter implants, which may have less risk of impinging upon neural structures, but are also less likely gain purchase in the denser bone of the $\mathrm{S} 1$ body due to their shorter length.

In addition to the fixation attempted in the index procedure, our revision approach involves decortication and graft placement. The blood and marrow exposed by decortication provide the vascularization, pluripotent mesenchymal stem cells, inflammatory re- sponse, and osteogenic factors conducive to bone formation and fusion. ${ }^{20,21}$ The decortication utilized

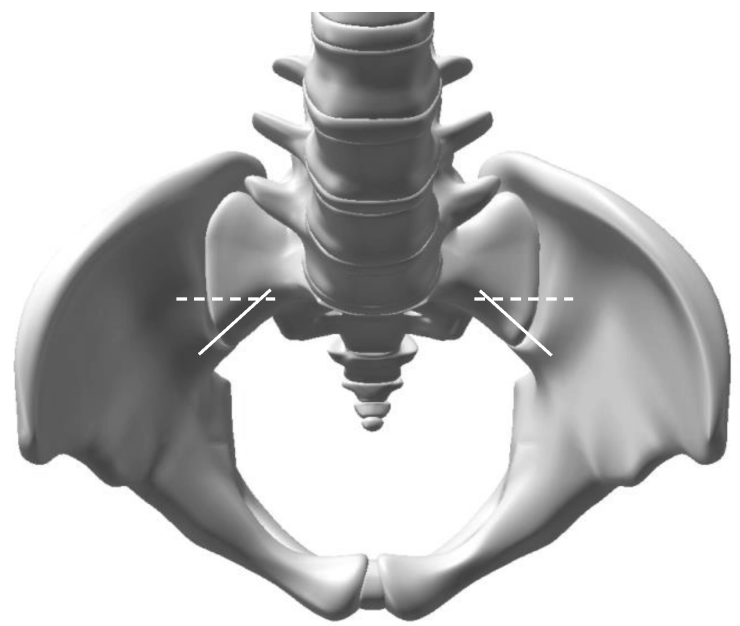

Fig. 5. Comparison of direct lateral-to-medial trajectory (dashed lines) and ventral-to-dorsal trajectory (solid lines).

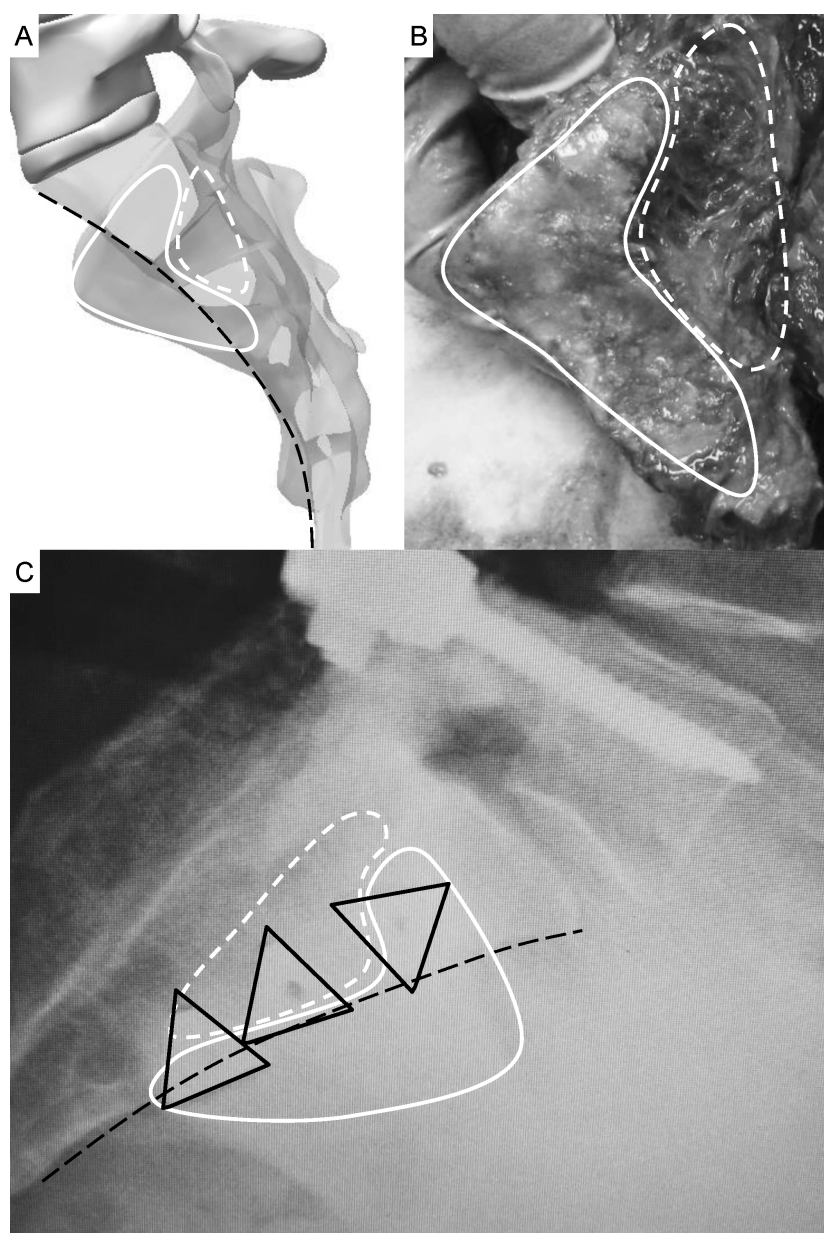

Fig. 6. Rendering (A), cadaveric dissection (B) and Case 1 pre-revision image (C), illustrating the relationship between the articular region (solid white lines), interosseous ligament region (dashed white lines), ventral sacral wall (dashed black lines) and pre-revision location of triangular implants (solid black lines). 
in these revision procedures is important to improve the likelihood of a solid union and long term improvement in SIJ symptoms. As described by Carter, skeletal mesenchymal stem cells may differentiate into fibrous, cartilaginous or bony tissue, depending on both the loading environment and vascularity. ${ }^{22,23} \mathrm{Ex}-$ cessive motion in the healing tissue may create tensile loading resulting in fibrous connective tissue formation, while insufficient vascularity - even with sufficient mechanical fixation - will promote chondrogenesis. We feel that the decortication, graft placement and fixation with threaded implants utilized in these revision procedures are all important to improve the likelihood of a solid union and long term improvement in SIJ symptoms.

As a final technical note, biplanar fluoroscopy was used to locate the cannulations in the triangular implants. Biplanar fluoroscopy provides simultaneous lateral $(\mathrm{X}-\mathrm{Y})$ and $\mathrm{AP}(\mathrm{X}-\mathrm{Z})$ feedback, which allows rapid navigation to the start point and orientation of the triangular implant cannulation. Therefore either biplanar or O-arm fluoroscopy are recommended if available to speed location and removal of existing implants.

Several limitations should be considered with respect to this study and the techniques described herein. Although the small cohort of patients followed in this case report were doing well at two to twelve months follow-up, it must be emphasized that this timeframe represents only the early-postoperative period.

Longer-term follow up in larger cohorts is needed to confirm both radiographic evidence of fusion and that the improvement in pain scores is maintained. In our practice this is particularly challenging, as the local population is often not available for long-term follow-up. It is notable that fusion rates with MI SIJ fusion systems are not well reported in the literature, ranging from $25 \%$ to $90 \%$. Regarding the triangular implant systems, Duhon et al. has reported that of 159 subjects with CT imaging at 12 months, bridging bone was seen in 39 cases (24.5\%) and Rudolf et al. reported evidence of bridging bone in $87 \%$ of cases at 5 years follow-up, while Kube et al. have reported $90 \%$ fusion at twelve months with the threaded implants. ${ }^{16,24,25}$ Clearly more study is needed to understand long-term clinical outcomes and fusion rates of both primary MI SIJ fusion procedures.

Several risks not observed in this small study must be considered, such as those common to index SIJ fixation (e.g., nerve impingement and recurrent sacroiliac joint pain), ${ }^{9}$ as well as those known with orthopedic revision procedures in general (e.g., re-revision, loosening and deep infection, especially in older patients). Risks unique to this revision strategy include graft extravasation through the initial implant holes and compromised bone stock due to the removal of the initially-placed implants. Notwithstanding these limitations, the revision strategy described in this case report was unanimously successful in four patients during a short-term follow up period.

\section{Conclusions}

Symptomatic nonunion after SIJ fixation surgery can be effectively revised in a minimally invasive fashion with positive outcomes. Removal of loosened implants is recommended, but the preservation of wellfixed implants does not appear to negatively affect short-term outcomes. Regardless of whether implants from the index procedure are removed, a ventral-to-dorsal trajectory is recommended. This trajectory is important not only for gaining fixation in undisturbed bone stock, but for placing the decortication and grafting in the center of the articular region of the joint, which we believe is critical in achieving long-term success through fusion. Careful consideration of patient-specific risks is a critical component of planning, and longer-term outcomes from a larger patient population is recommended before broadly generalizing the results observed in this case-series.

\section{References}

1. Andersson GB. Epidemiological features of chronic low-back pain. Lancet. 1999;354(9178):581-5. 2. Sembrano JN, Polly DW, Jr. How often is low back pain not coming from the back? Spine (Phila $\mathrm{Pa}$ 1976). 2009;34(1):E27-32.

3. Cohen SP. Sacroiliac joint pain: a comprehensive review of anatomy, diagnosis, and treatment. Anesth Analg. 2005;101(5):1440-53. 
4. Maigne JY, Planchon CA. Sacroiliac joint pain after lumbar fusion. A study with anesthetic blocks. Eur Spine J. 2005;14(7):654-8.

5. Schwarzer AC, Aprill CN, Bogduk N. The sacroiliac joint in chronic low back pain. Spine (Phila Pa 1976). 1995;20(1):31-7.

6. Smith AG, Capobianco R, Cher D, Rudolf L, Sachs D, Gundanna M, et al. Open versus minimally invasive sacroiliac joint fusion: a multi-center comparison of perioperative measures and clinical outcomes. Ann Surg Innov Res. 2013;7(1):14.

7. Whang P, Cher D, Polly D, Frank C, Lockstadt $\mathrm{H}$, Glaser J, et al. Sacroiliac Joint Fusion Using Triangular Titanium Implants vs. Non-Surgical Management: Six-Month Outcomes from a Prospective Randomized Controlled Trial. Int J Spine Surg. 2015;9:6.

8. Polly DW, Cher DJ, Wine KD, Whang PG, Frank CJ, Harvey CF, et al. Randomized Controlled Trial of Minimally Invasive Sacroiliac Joint Fusion Using Triangular Titanium Implants vs Nonsurgical Management for Sacroiliac Joint Dysfunction: 12-Month Outcomes. Neurosurgery. 2015;77(5):674-90; discussion 90-1.

9. Miller LE, Reckling WC, Block JE. Analysis of postmarket complaints database for the iFuse SI Joint Fusion System(R): a minimally invasive treatment for degenerative sacroiliitis and sacroiliac joint disruption. Med Devices (Auckl). 2013;6:77-84. 10. Cher DJ, Reckling WC, Capobianco RA. Implant survivorship analysis after minimally invasive sacroiliac joint fusion using the iFuse Implant System((R)). Med Devices (Auckl). 2015;8:485-92. 11. Szadek KM, van der Wurff $P$, van Tulder MW, Zuurmond WW, Perez RS. Diagnostic validity of criteria for sacroiliac joint pain: a systematic review. J Pain. 2009;10(4):354-68.

12. Hansen HC, McKenzie-Brown AM, Cohen SP, Swicegood JR, Colson JD, Manchikanti L. Sacroiliac joint interventions: a systematic review. Pain physician. 2007;10(1):165-84.

13. Manchikanti L, Abdi S, Atluri S, Benyamin RM, Boswell MV, Buenaventura RM, et al. An update of comprehensive evidence-based guidelines for interventional techniques in chronic spinal pain. Part II: guidance and recommendations. Pain physician. 2013;16(2 Suppl):S49-283.
14. Beaubien B, Salib RM, Fielding LC, Block JE. SImmetry Sacroiliac Joint Fusion System with SImmetry Decorticator. Surgical Science.

2015;06(07):282-91.

15. Miller LE, Block JE. Minimally invasive arthrodesis for chronic sacroiliac joint dysfunction using the SImmetry SI Joint Fusion system. Med Devices (Auckl). 2014;7:125-30.

16. Rudolf L, Capobianco R. Five-year clinical and radiographic outcomes after minimally invasive sacroiliac joint fusion using triangular implants. Open Orthop J. 2014;8:375-83.

17. Roth TD, Maertz NA, Parr JA, Buckwalter KA, Choplin RH. CT of the hip prosthesis: appearance of components, fixation, and complications. Radiographics : a review publication of the Radiological Society of North America, Inc. 2012;32(4):1089-107. 18. Vleeming A, Volkers AC, Snijders CJ, Stoeckart R. Relation between form and function in the sacroiliac joint. Part II: Biomechanical aspects. Spine (Phila Pa 1976). 1990;15(2):133-6.

19. Ebraheim NA, Mekhail AO, Wiley WF, Jackson WT, Yeasting RA. Radiology of the sacroiliac joint. Spine (Phila Pa 1976). 1997;22(8):869-76.

20. Friedenstein AJ, Petrakova KV, Kurolesova AI, Frolova GP. Heterotopic of bone marrow. Analysis of precursor cells for osteogenic and hematopoietic tissues. Transplantation. 1968;6(2):230-47.

21. Muschler GF, Lane JM, Dawson EG. The Biology of Spinal Fusion. In: Cotler JM, Cotler HB, editors. Spinal Fusion: Science and Technique. New York, NY: Springer New York; 1990. p. 9-21.

22. Carter DR. Mechanical loading history and skeletal biology. Journal of biomechanics.

1987;20(11-12):1095-109.

23. Carter DR, Beaupre GS, Giori NJ, Helms JA. Mechanobiology of skeletal regeneration. Clin Orthop Relat Res. 1998(355 Suppl):S41-55.

24. Duhon BS, Bitan F, Lockstadt H, Kovalsky D, Cher D, Hillen T. Triangular Titanium Implants for Minimally Invasive Sacroiliac Joint Fusion: 2-Year Follow-Up from a Prospective Multicenter Trial. Int J Spine Surg. 2016;10:13.

25. Kube RA. Sacro-Iliac Fusion Rates Using a Novel MIS System. 15th Annual Meeting of the International Society for the Advancement of Spine Surgery; 2015 April 15-17, 2015; San Diego, CA. 


\section{Disclosures \& COI}

Dr. Brett Menmuir and Louis C Fielding are paid consultants to Zyga Technology.

\section{Corresponding Author}

Brett MenMuir, MD, Reno Orthopaedic Clinic, 555

N Arlington Ave., Reno, NV 89503.

\section{Brettm@renoortho.com}

Published 27 February 2017.

This manuscript is generously published free of charge by ISASS, the International Society for the Advancement of Spine Surgery. Copyright @ 2017 ISASS. To see more or order reprints or permissions, see http://ijssurgery.com. 